\title{
Mulheres no Sistema Prisional e Direitos Humanos
}

\author{
Renata Pereira Lopes de Oliveira
}

(Aluna do curso de Direito PUC RIO)

Ressignificar e revisitar a perspectiva da ética socioambiental e dos direitos humanos no contemporâneo, implica em refletir sobre a prática viva e constante de cada indivíduo/cidadão, que não se constrói de forma neutra, bem como compreender sobre as concepções de cidadania, numa dimensão ética/moral, respectivamente na formação contínua do cidadão, tal como ser solidário, cooperativo, responsável consigo e com os outros, entender-se em seus direitos e deveres, ser tolerante nas religiões, ter embasamento em valores, crenças e viver dignamente com completude. Com isso, a Declaração Universal dos Direitos Humanos perpassa por anos como um instrumento inspirador e norteador em 7 dimensões: Ética, Jurídica, Política, Econômica, Social, Cultural e Educativa no entorno de valores e princípios propícios que assegurem uma sociedade baseada na igualdade, liberdade e fraternidade no sentido de humanidade, visando o cumprimento das leis cabíveis aos cidadãos e aos nossos representantes.

Assim, o contraste desse texto "Mulheres no Sistema Prisional e Direitos Humanos", visa fazer uma interlocução considerável à luz da Ética Socioambiental e do atual cenário do Sistema Carcerário Brasileiro, mas especificamente mulheres, com base em dados do ENFOPEM da última atualização (2014), relatos oficiais de prisioneiras nos escritos de Nanda Queiroz em seu livro : "Presos que Menstruam - A brutal vida das mulheres - tratadas como homens - nas prisões brasileiras" (2016) e é claro, em algumas ressalvas da Declaração:

Artigo $3^{\circ}$ - Todo indivíduo tem direito à vida, à liberdade e à segurança pessoal. 
Artigo $5^{\circ}$ - Ninguém será submetido a tortura nem a penas ou tratamentos cruéis, desumanos ou degradantes.

Artigo $9^{\circ}$ - Ninguém pode ser arbitrariamente preso, detido ou exilado.

Artigo $12^{\circ}$ - Ninguém sofrerá intromissões arbitrárias na sua vida privada, na sua família, no seu domicílio ou na sua correspondência, nem ataques à sua honra e reputação. Contra tais intromissões ou ataques toda a pessoa tem direito a proteção da lei.

Artigo $25^{\circ}$ - 1. Toda a pessoa tem direito a um nível de vida suficiente para lhe assegurar e à sua família a saúde e o bemestar, principalmente quanto à alimentação, ao vestuário, ao alojamento, à assistência médica e ainda quanto aos serviços sociais necessários, e tem direito à segurança no desemprego, na doença, na invalidez, na viuvez, na velhice ou noutros casos de perda de meios de subsistência por circunstâncias independentes da sua vontade. 2. A maternidade e a infância têm direito a ajuda e a assistência especiais. Todas as crianças, nascidas dentro ou fora do matrimônio, gozam da mesma proteção social.

O viés para tal reflexão são as mulheres encarceradas que são abandonadas pela família e amigos, segundo Souza, acabam por sofrer mais intensamente o processo de prisonização, pois têm maior necessidade de integração ao grupo da prisão. São distanciadas de todos os afetos externos, acabam criando uma dependência da unidade prisional, das outras internas e dos funcionários que ali se encontram. É uma característica bastante vigente nesse meio. Toda a vulnerabilidade, sensibilidade das mulheres ficam à mercê de seus próprios monstros internos, imaginários. O apoio das famílias é a sobrevivência garantida, o mundo exterior retrata esperança e aconchego, como mudança de comportamento, pois "é da família que elas recebem apoio moral, emocional e, frequentemente, material" e ainda complementa dizendo que o dia de visita "é esperado 
com ansiedade e, para muitas, motivo que as estimula a ter 'bom comportamento"'. (SANTOS,2012)

Os motivos para que elas passem por isso e por muitas outras coisas, implica em uma sociedade capitalista na qual prevalece quem tem poderes aquisitivos e que mantém a desordem, a pobreza, injustiças e um desenvolvimento social vagaroso e desfavorável. Quantas presas estavam submetidas a um companheiro violento e opressor, ou roubaram para alimentar seus filhos, ou por serem usuárias de drogas (Artigo 9o - Ninguém pode ser arbitrariamente preso, detido ou exilado). Nossa sociedade opera nesse sentido de forma diferente e desigual. Os motivos justificam os meios que habitam e a ausência de capital cultural, social etc.

Para ilustrar o quadro atual do sistema carcerário geral do País, quatro conjuntos de informações disponibilizam indagações e reflexões sobre esse universo esquecido pela sociedade e de pouco interesse para estudos. Dados do ENFOPEM. 


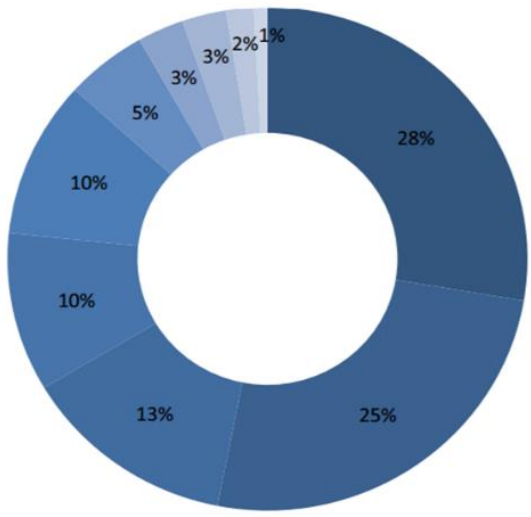

- Tráfico de drogas

$$
\text { - Roubo }
$$

Eurto

Homicídio

=utros

m Estatuto do desarmamento

" Receptação

$=$ Latrocinio

m Quadrilha ou bando

= Violência doméstica

Fonte: Infopen, dez/2014.

Distribuição por faixa etária no sistema prisional e na população brasileira

$46,09 \%$

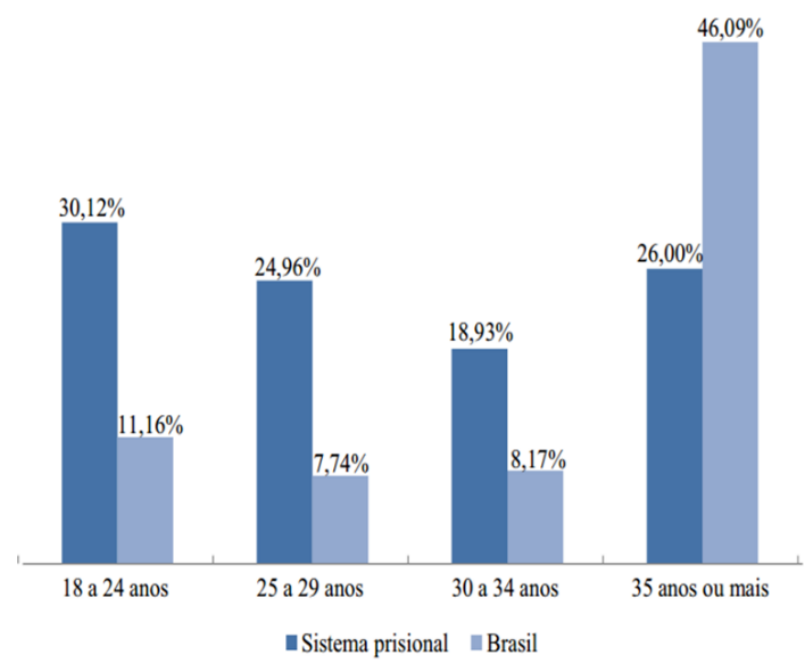

Fonte: Infopen, dez/2014. PNAD, 2014 

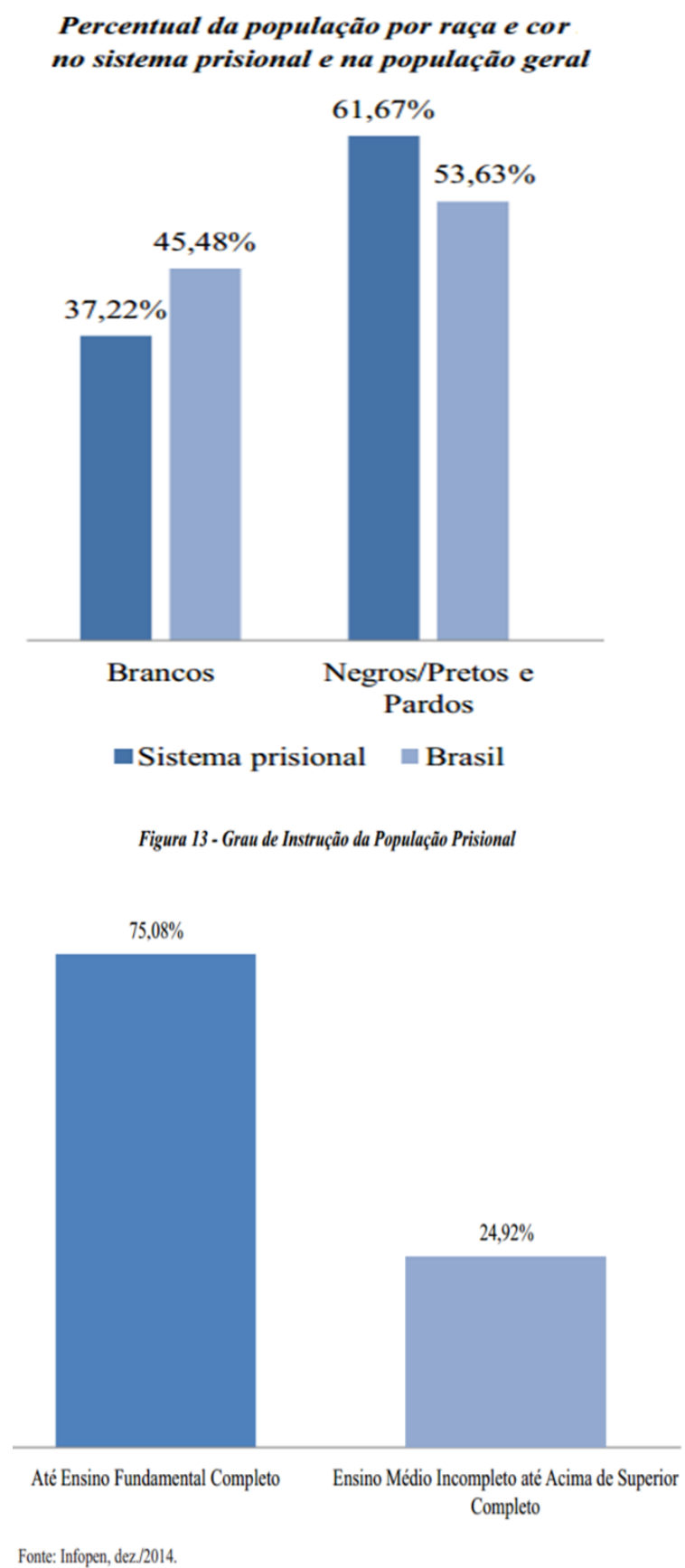

"No Brasil, segundo o Ministério de Justiça, entre 2003 e 2007 houve um crescimento de $24,87 \%$ na população prisional masculina, enquanto o aumento feminino foi $37,47 \%$ no mesmo período" (BRASIL, 2008).

Os dados do ENFOPEN, mostram no primeiro gráfico algumas razões para o encarceramento de homens e mulheres, $28 \%$ são presos por tráfico de drogas, esse número 
é significativo pelas mulheres, esposas, que aceitam e se submetem a ajudar seus parceiros nesse ramo, sendo presas permanentes e alvos fáceis.

A maioria das mulheres são presas por envolvimento com drogas. Geralmente, são flagradas com uma quantidade mínima, pois muitas são usuárias ou dependentes. Pobreza e dependência química são os fatores que mais desencadeiam a entrada de mulheres na criminalidade. Devido a isso, há uma necessidade urgente de programas para tratamento de dependência química, assim como há necessidade de se pensar caminhos para o emprego após a soltura, juntamente com programas que ajudem estas mulheres a lidarem com o trauma psicológico de abusos pré e pós encarceramento. (QUEIROZ,2016)

Entre 18 a 24 anos de idade há uma proporção também muito grande de $30,12 \%$ de envolvidos no crime. Se falarmos de raça/cor, negros/pretos e pardos esse número ainda é maior com $61,67 \%$ de pessoas presas e por escolaridade se torna um índice bastante gritante. Todos esses números envolvem mais mulheres do que homens, considerando o grau de jovens encarceradas e o número de grávidas, nossa reflexão vai muito mais além.

A Lei de Execução Penal e Maternidade, garante acompanhamento médico, principalmente no pré-natal e pósparto, extensivo ao recém-nascido. Garante, também, estabelecimentos com berçários e o direito de a mulher cuidar do filho e amamentá-lo, no mínimo, até seus 06 meses de idade. Ainda, prevê creche para crianças entre 06 meses e 07 anos (BRASIL 2015).

Nana Queiroz, descreve em seu livro, uma realidade cruel, brutal e completamente desumana, no sistema carcerário que viola criminalmente o direito da mãe ter seu bebê no mínimo possível de dignidade. Uma das detentas teve seu bebê dentro de uma viatura policial porque não tinha outro transporte para fazer o devido percurso. No caminho foi 
violentada pelos policiais, deixando-a com marcas e ossos quebrados, chegando ao hospital disseram que sofreram um acidente no caminho, o sistema considerou apenas uma fala, ela chegou inconsciente e viu o seu bebê depois de horas de nascido, porque as enfermeiras não estavam dispostas a subir no $4^{\circ}$ andar para pegá-lo porque o elevador estava em manutenção. Após tudo isso, algemada constantemente voltou para cela, vive com o bebê de dois meses em um espaço medíocre, sem luz solar, apenas com uma bacia, um colchão no chão, alguns panos e um fedor insuportável, a criança com a idade "adequada" se separará da mãe para adoção, ou para algum parente, o que muitas vezes não acontece. Ambas, perderão seus direitos. Apenas 34\% das prisões do país têm celas para gestantes, $30 \%$ possui berços, e só $5 \%$ têm creches. Existe realmente bebês encarcerados. Apesar de estar previsto no Código de Processo Penal, a Justiça entende que a concessão dos benefícios às gestantes não é automática e depende da análise individual da situação de cada detenta.

Somente a partir da análise da situação da detenta, pode ser feita uma avaliação à luz dos dos artigos da Declaração, como no Artigo $5^{\circ}$ : "Ninguém será submetido a tortura nem a penas ou tratamentos cruéis, desumanos ou degradantes". O valor da vida perdeu sua essencialidade para a detenta, também no Artigo $25^{\circ}$ do inciso 2 da Declaração dos Direitos humanos: "A maternidade e a infância têm direito a ajuda e a assistência especiais. Todas as crianças, nascidas dentro ou fora do matrimônio, gozam da mesma proteção social". Vimos que esta criança já encarou o mundo da pior forma possível, sem um ambiente seguro e feliz, sem assistência própria e recursos específicos para manter a saúde e conforto.

Por fim, o fundamento natural dos direitos humanos é colocado pela Doutrina Social da Igreja na dignidade humana. Tais direitos são universais, invioláveis e inalienáveis. A universalidade está relacionada ao fato de esses direitos estarem presentes em todos SERES HUMANOS sem 
nenhuma distinção. Invioláveis porque são inerentes à pessoa humana e à sua dignidade e porque de nada valeria proclamar tais direitos, se ao mesmo tempo não se fizer um esforço, de modo a que seja devidamente assegurado o seu respeito por todos. Por último são inalienáveis porque não se pode legitimamente privar destes direitos um seu semelhante, já que isso significaria violentar a sua própria natureza. Esses direitos não são simplesmente concedidos pelo legislador: eles são declarados. Uma sociedade justa e ética está centrada no respeito incondicional à dignidade humana. $\mathrm{A}$ pessoa humana, em nenhuma hipótese, pode ser instrumentalizada para fins alheios a este que não seja a concretização de sua dignidade.

\section{Referências:}

- http://www.onu.org.br/img/2014/09/DUDH.pdf

- QUEIROZ Nana. Presos que Menstruam. - 6ª edição. - Rio de Janeiro: Record,2016.

- https://david12345678.jusbrasil.com.br/artigos/172397634/atomada-de-consciencia-dos-direitos-humanos-nocristianismo

- BRASIL, Ministério de Justiça, Departamento Penitenciária Nacional. População Carcerária Brasileira (Quinquênio 20032007): Evolução e Prognósticos. Brasília, DF, 2008.

- http://www.domhelder.edu.br/revista/index.php/veredas/articl e/view/6/5

- Caderno Espaço Feminino - Uberlândia-MG - v. 25, n. 1 Jan./Jun. 2012 - ISSN online 1981-3082

- http://www.seer.ufu.br/index.php/neguem/article/view/15095/ $\underline{11088}$ 